\title{
客房部实习生培训现状分析及改进策略研究 ---以杭州千岛湖喜来登度假酒店为例
}

\author{
石丽璠 \\ 广西师范大学漓江学院 \\ DOI:10.32629/mef.v3i5.915
}

\begin{abstract}
[摘 要] 近年来各地高星级酒店不断增加, 酒店业劳动力竞争加大, 很多酒店通过与学校签订协议接 收大量的实习生。本文通过分析杭州千岛湖喜来登度假酒店客房部实习生的培训现状, 发现存在培训 时间安排不合理、培训程序不规范、对实习生的培训不到位以及不能按照计划进行培训等问题, 提出 酒店客房部应合理安排培训时间、规范培训程序、合理制定培训内容、将培训落到实处, 期望酒店能 够为实习生开展切实有效的岗位培训，提高其对客服务质量。
\end{abstract}

[关键词] 喜来登度假酒店; 客房部; 实习生培训

\section{Analysis on the Status Quo of Intern Training in Housekeeping Department and Research on Improvement Strategies \\ — Take Sheraton Hangzhou Qiandao Lake Resort as an Example}

Lifan Shi

Lijiang College, Guangxi Normal University

\begin{abstract}
[Abstract] In recent years, the number of high-star hotels has been increasing, and labor competition in the hotel industry has increased. Many hotels have signed agreements with schools to accept a large number of interns. This article analyzes the current situation of the training of interns in the guest room department of Sheraton Hangzhou Qiandao Lake Resort, and finds that there are problems such as unreasonable training schedule, irregular training procedures, inadequate training for interns, and inability to conduct training as planned. It proposed that training time should be reasonably arranged, training procedures should be standardized, training content should be reasonably formulated, and training should be implemented, and expected that the hotel can carry out practical and effective on-the-job training for interns and improve the quality of their customer service.
\end{abstract}

[Key words] Sheraton Resort; the guest room department; the training of interns

1 杭州千岛湖喜来登度假酒店 客房部培训现状
1. 1 千岛湖喜来登度假酒店客房部 概况

杭州千岛湖喜来登度假酒店位于浙 江省淳安县千岛湖镇, 是一家以休闲度

[参考文献]

[1]王宗礼,周方.网络新媒体对高校 意识形态安全的冲击及应对 [J]. 思想教 育研究,2018(10):125-128.

[2]潘舒展.网络新媒体发展现状与问 题研究[J].科技传播,2018,10(9):155-156.

[3]王艾娟,胡圣知、网络社交媒体对 高校意识形态的影响与引导策略研究 [J].新闻战线,2018(08):139-140.

[4]寇翔. “互联网+”时代高校主流
意识形态教育的技术路径选择[J].河南 教育(高教),2018(01):55-57.

[5]李㳙.网络新媒体对青少年意识形 态领域的影响[J]. 电子商务,2017(1):13-14.

[6]李俊卿, 张泽一. 互联网背景下国 家意识形态表征、安全风险及防范 [J]. 思想理论教育导刊,2016(10):85-89.

[7]程丹.网络新媒体发展现状及问 题分析[J]. 科技创新与应用,2016(12):80.

[8]吴迪铭. “互联网+”视角下高校
网络意识形态建设路径探究 [J]. 新西 部,2018(15):131+149.

\section{作者简介:}

唐林 (1999--), 男, 汉族, 安徽 池州人，常州信息职业技术学院数字经 济学院市场营销专业2018级专科生。

曹建(1991--)，男，汉族，江苏常 州人, 讲师, 硕士，研究方向：思想政 治教育。 
假为主，商务会议为辅的综合性五星级 酒店。客房部是酒店营运中的一个重要 部门, 隶属于酒店房务部, 共设有四个 小部门: PA (Public Area)、洗衣房、 健身中心、楼层服务。由于其独特的服 务性质, 从而使形成了客房部以楼层服 务为主, 其他部门为辅, 相互协作的性 质。

1. 2 杭州千岛湖喜来登度假酒店客 房部实习生培训概况

1. 2. 1杭州千岛湖喜来登度假酒店 客房部接收实习生情况

近年来由于各地高星级酒店不断增 加, 人力资源需求也相应不断扩大, 具 有丰富管理经验或者高学历的人才成为 各大酒店争夺的重点对象, 雇佣实习生 也成为解决酒店人力资源配置问题的极 佳途径。杭州千岛湖喜来登度假酒店客 房部原有正式员工 (楼层服务员) 10 名, 文员 1 名, 楼层主管 3 名, 行政管家 1 名, 行政副管家 1 名, 实习生总数 29 名。实习 生所占比重为 $64 \%$, 正式员工所占比例为 $35 \%$ 。实习生比例远远大于正式员工比 例。因此, 如何正确科学的培训与管理 实习生, 如何正确发挥实习生优势, 已 经显得尤为重要。

1.2.2客房部对实习生培训的内容

酒店会在每批实习生正式上岗的前 三天对实习生进行系统的理论技能培 训。培训内容包括: 酒店简介和酒店基 本概况、酒店的规章制度、酒店以及酒 店所属集团的核心价值、酒店明星服务 标准以及一些基本的服务程序、酒店各 部门的介绍、消防急救措施介绍、参观 各部门等。

随后酒店就将客房部实习生交给客 房部。客房的实习生在刚开始的一个月, 每周主管都会组织实习生进行客房工作 内容的培训, 培训内容包括: 客房摆设 以及客房内设备设施使用; 做房 $\mathrm{ABCs}$ 程 序; 酒店卫生标准; 处理突发事件及客 人投诉; 仪容仪表; 酒店客房英语培训。 之后还有不定期的进行杯具消毒, 清洁 剂识别培训等。但是客房部后期的培训 大部分是基于事故的基础上进行培训, 当实习生出现问题时再进行培训。基本
都是让老员工带着实习生, 直至他们能 独立完成工作任务。

\section{2 杭州千岛湖喜来登度假酒店 客房部培训存在问题分析}

在千岛湖喜来登度假酒店, 酒店的 培训通常由人力资源部负责。实习生进 入客房部以后虽然部门也针对实习生 进行了一些培训, 但是基本是在比较仓 促的情况下完成的, 其中存在着一定的 问题。

2.1培训时间安排不合理

2.1.1酒店规定各个部门每周至少 培训两次, 每次培训不少于 2 小时。客 房部也根据酒店规定制定了培训安排, 在周一至周四不同时间安排培训。但是 客房部是提前将每一项培训内容安排 在固定的时间后再下发通知, 实习生的 排班时间不一样, 这就造成部门部分实 习生没有得到培训。而且培训时间基本 固定在15-17点或者17点-19点, 前一个 时间大多数实习生尚未完成工作, 故不 能参加培训, 后一个培训与实习生用餐 时间相冲突, 因此实习生往往选择不参 加培训。

2.1.1客房部安排日常英语培训时 是在早会之后, 此时正是退房时间, 大 部分实习生都忙于查房, 因此这项培训 最终停止进行。

\section{2 缺乏规范的培训程序}

培训是一种有组织的知识传递、技 能传递、标准传递、信息传递、信念传 递、管理训诫行为。千岛湖喜来登度假 酒店客房部往往把培训当成 “治病”, 而不是 “强身”, 有时是在工作中出现 问题才临时抱佛脚。例如客房部主要工 作之一是清洁, 因此清洁类药剂种类较 多, 而实习生上岗前并未进行相关培 训, 导致在一次客房清洁过程中实习生 把不锈钢清洗剂和木制家具抛光剂搞 混, 将不锈钢清洁剂当做木制家具抛光 剂使用, 造成家具损坏。事后客房部主 管立即在早会时安排了 20 分钟对实习 生进行紧急培训, 但是在培训方法上大 多还是采用传统的口头讲授方式, 没有 规范的文字培材料, 导致培训工作带有 很大的随意性。实习生在培训后对药剂
认识依旧不清晰, 在工作中仍然存在隐 患。

2. 3对实习生的培训不到位

实习生进入部门以后, 客房部安排 了一定的系统化培训, 例如做房程序 $\mathrm{ABCs}$; 客房设施设备的熟悉以及使用; 杯具正确的消毒程序等。但是酒店工作 人员流失较大, 客房部工作任务繁重, 培训往往占用工作时间。因此工作与培 训间的矛盾日益突出。在学生实习期间 未涉及到的培训内容有很多, 包括白金 套房的清洁程序; 计划卫生的内容及完 成程序; 客房定期大清洁的程序; 客房 部opera系统的学习。酒店面对大量工 作任务时却要求实习生完成尚未培训 过的工作, 往往会导实习生完成的工作 质量不符合酒店标准, 这样不仅增加了 工作量同时也打击了实习生的工作热 情, 实习生的业务素质也始终得不到有 效提高。

2. 4不能按照培训计划进行培训

实习生进入部门实习时间通常正值 酒店入住高峰期, 每日住房率高, 工作 量大。部门不能按照计划在规定的培训 时间里完成规定的培训内容。在入住率 降低后也未对实习生进行常规培训, 同 时也未将旺季时没有进行的培训内容进 行重新培训。每个月末酒店按照常规会 对实习生的培训内容进行抽查, 部门主 管要求实习生在酒店下发给各部门的培 训安排表上签字确认，但实际上实习生 并未进行相关培训。

\section{3 杭州千岛湖喜来登度假酒店 客房部培训问题对策研究}

客房部是酒店的重要部门之一，杭 州千岛湖喜来登度假酒店客房部在实习 生培训上存在不少问题, 下面提出一些 解决的策略:

3. 1 合理安排培训时间

客房部实习生培训是否做到位直接 关系到实习生工作质量, 所以需要对培 训时间进行合理化安排。可以考虑将培 训时间与工作时间相互错开，安排在下 午做完房后并且避免和用餐时间相冲 突。同时将培训安排在酒店住房率较低 的时间，并做好通知工作，及时通知未 
上班的实习生参加培训。对因工作时间 冲突未能培训的实习生, 做好记录, 并 在适当的时间安排其参加培训。

\section{2 培训程序规范化}

正确的培训程序才能保证使实习生 在实际工作中减少出现不必要的失误。 客房部无论因为何种原因，都应该克服 困难让实习生先培训再上岗。实习生优 秀的工作能力以及解决突发事件的能 力, 都需要以扎实的理论知识为基础。 同时培训内容应该以规范的文字材料呈 现出来, 客房部工作内容繁琐, 将培训 内容书面化有利于实习生不断地学习巩 固和复习, 同时培训后还可以定期对实 习生进行考核, 通过考核理论知识和实 践知识, 确保培训的有效性。

3. 3培训内容合理化

培训人员应该从部门工作实际的需 求出发, 合理制定实习生培训计划, 明 确培训的具体内容。客房部需要实习生 做什么, 实习生在工作中要怎么做, 培 训人员都要拟定好培训计划, 对于实习 生在工作岗位上可能需要掌握的知识, 都应该合理地安排到培训内容当中。对 暂时尚未培训到的内容, 部门培训人员 应该做好记录工作，并适时安排培训。

3. 4 将培训落到实处
如果没有特殊情况, 部门应该在规 定的培训时间里完成规定的培训任务, 切实有效地将培训落到实处。如果因为 客观原因造成培训不能如期进行, 部门 主管应及时与酒店人力资源部和酒店管 理层进行沟通, 将培训延后。在酒店入 住率较低时, 及时安排实习生开展培训, 不能因时间安排冲突就主观决定不进行 或者减少培训。

\section{4 结语}

总而言之, 21 世纪最为缺少的并非 是资源, 而是人才, 酒店要想在日趋激 烈的市场竞争中稳步取胜, 需要在激烈 的人才竞争中立于不败之地。除了对优 秀人才加以招揽外, 还应该对既有员工 的培训加以高度重视。实习生作为酒店 员工的重要组成部分, 其服务质量的高 低对整个酒店有着重要影响。客房部作 为酒店其中一个最重要的部门, 同样应 该对包括实习生在内的员工积极地开 展培训, 在此过程中要尽快地转变发展 和管理观念, 有针对性、有目的地制定 出完善的培训计划, 采取科学可行的培 训方式, 以此提升酒店客房部甚至整个 酒店员工服务质量, 形成酒店的核心竞 争力。

\section{[基金项目]}

广西师范大学漓江学院2017年教育 教学改革研究项目 (校级A类): 基于校 企协同育人机制的应用型本科院校旅游 管理和酒店管理专业人才培养模式改革 研究。

\section{[参考文献]}

[1]徐利民,仇南海.浅谈酒店人力资 源的管理 [J].苏盐科技.2010(2):31-33.

[2]梭伦.现代宾馆酒店人力资源管 理 [M]. 北京: 中国纺织出版社, 2001.

[3]李长来.酒店员工培训对策 [J]. 企业研究.2008(1 1):41-42.

[4]王秀妹.浅析企业员工培训存在 问题及对策 [J]. 中国科技信 息.2005(21):326。

[5]孙淑英.浅谈企业如何做好新员 工的培训及管理工作 [J]. 民营科 技.2009(11):99.

[6]张天野. 大连汉庭酒店员工培训 方案设计[D].沈阳理工大学,2017.

[7]权锡哲，魏冠明.新员工培训管 理实务手册[M].人民邮电出版社2012.5.

\section{作者简介：}

石丽璠（1980--)，女，汉族，广 西桂林市人, 副教授, 硕士, 研究方向: 旅游教育、旅游文化。 